Check for updates

Cite this: Chem. Commun., 2017, 53, 12524

Received 1st August 2017,

Accepted 22nd September 2017

DOI: $10.1039 / c 7 c c 06022 j$

rsc.li/chemcomm

\section{Siloxane-based linkers in the construction of hydrogen bonded assemblies and porous 3D MOFs $\dagger$}

\author{
Luke C. Delmas, (D) ${ }^{a}$ Peter N. Horton, ${ }^{b}$ Andrew J. P. White, (D) ${ }^{a}$ Simon J. Coles, (D) ${ }^{b}$ \\ Paul D. Lickiss (D) *a and Robert P. Davies (D)*a
}

\begin{abstract}
A siloxane-based hexacarboxylic acid $\left(\mathrm{L} 1-\mathrm{H}_{6}\right)$ has been prepared and applied in MOF construction. $\mathrm{L} 1-\mathrm{H}_{6}$ itself crystallizes as an unusual interpenetrated 3D hydrogen-bonded framework. Reaction of $\mathrm{L} 1-\mathrm{H}_{6}$ with $\mathrm{Zn}(\mathrm{II})$ gave IMP-18 - a 3D MOF incorporating Si-O-Si functionality. Cleavage of $\mathrm{L} 1-\mathrm{H}_{6}$ gives a silanol-based triacid which is shown to give a coordination polymer (IMP-19) with $\mathrm{Zn}(\mathrm{II})$.
\end{abstract}

The rapid growth in research on metal-organic frameworks (MOFs) has largely relied upon the use of commercially available organic linkers. ${ }^{1,2} \mathrm{~A}$ further step towards the rational design of functional MOFs (through fine-tuning of these materials' topological and chemical properties) requires the synthesis of novel ligands with unique structural and chemical features. ${ }^{3,4}$ We have been interested for some time in the synthesis of highly branched organosilicon linkers and their use in the assembly of MOFs, largely due to their synthetic accessibility compared to their carbon-centred analogues. ${ }^{5-10}$ However, despite the siloxane linkage (Si-O-Si) being ubiquitous in many classes of materials including zeolites, ${ }^{11,12}$ periodic mesoporous organosilicas, ${ }^{13,14}$ POSS hybrids and other porous materials, ${ }^{15,16}$ we were surprised to find that there has been little interest in siloxane-based linkers ${ }^{17-21}$ for MOFs, and that their incorporation into a porous 3D MOF has not been reported to date. We have thus recently focussed upon the development of siloxane-based polycarboxylates, and report herein the synthesis of the novel pseudooctahedral hexa(4-carboxyphenyl)disiloxane molecule $\left(\mathbf{L 1}-\mathrm{H}_{6}\right)$, its unusual hydrogen bonded network assembly and its application in the preparation two new MOF materials.

\footnotetext{
${ }^{a}$ Department of Chemistry, Imperial College London, South Kensington,

London SW7 2AZ, UK. E-mail: r.davies@imperial.ac.uk, p.lickiss@imperial.ac.uk

${ }^{b}$ EPSRC Crystallographic Service, Department of Chemistry,

University of Southampton, Highfield, Southampton SO17 1BJ, UK

$\dagger$ Electronic supplementary information (ESI) available: Full experimental details of the synthesis, characterisation data and the crystallographic protocols employed in this study. PXRD and TGA plots for IMP-18 and IMP-19 and $\mathrm{N}_{2}$ sorption isotherm for IMP-18. Details of additional topological analyses for structures are also presented. CCDC 1566035-1566037. For ESI and crystallographic data in CIF or other electronic format see DOI: $10.1039 / \mathrm{c} 7 \mathrm{cc} 06022 \mathrm{j}$
}

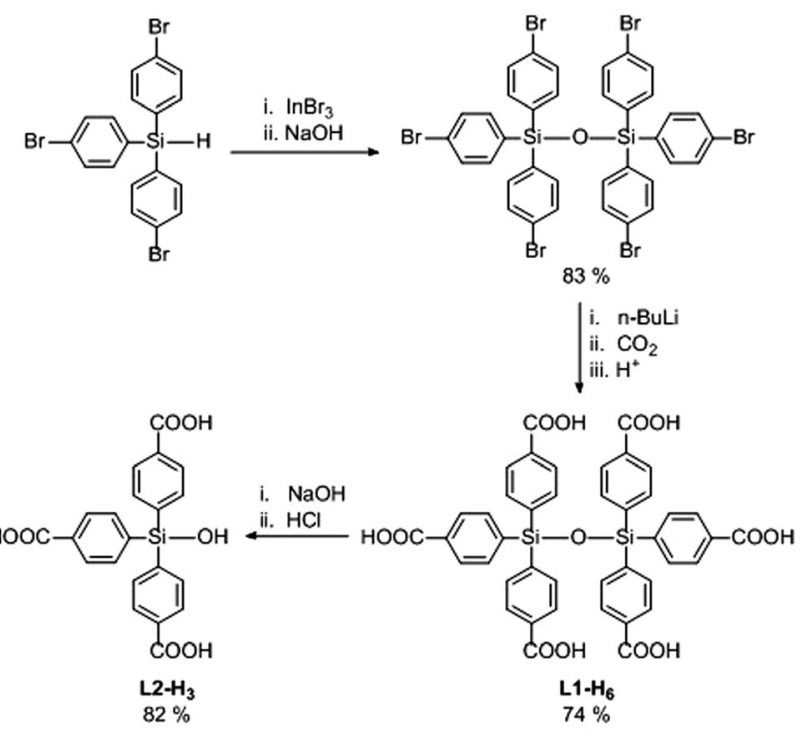

Scheme 1 Synthesis of $\mathbf{L} \mathbf{1}-\mathrm{H}_{6}$ and $\mathbf{L} \mathbf{2}-\mathbf{H}_{3}$.

The synthesis of $\mathbf{L 1}-\mathrm{H}_{6}$ is outlined in Scheme 1. Firstly, tris(4bromophenyl)silane ${ }^{22}$ was converted to the corresponding hexasubstituted disiloxane via modification of an In(III)-catalysed protocol for hydrosilane oxidation. ${ }^{23}$ The sterically protected siloxane linkage withstood subsequent treatment with $n-\mathrm{BuLi}$, allowing reaction of the polylithiated intermediate with $\mathrm{CO}_{2}$ to afford $\mathbf{L 1}-\mathrm{H}_{6}{ }^{8}{ }^{8}$ Treatment of $\mathbf{L} 1-\mathrm{H}_{6}$ with base, followed by acid work-up, gave the tris-carboxylic acid silanol derivate $\mathbf{L} 2-\mathrm{H}_{3}$. The presence of strongly polar $\mathrm{Si}-\mathrm{OH}$ groups in the pores of MOFs could potentially lead to enhanced non-covalent interactions with gas molecules giving rise to attractive adsorption properties. ${ }^{24,25}$

In some situations, polycarboxylic acids have been shown to form porous frameworks on crystallisation through hydrogen bonding. ${ }^{26}$ Moreover, some of these materials have demonstrated potential for gas storage and separation applications..$^{27,28}$ Given $\mathbf{L 1}-\mathrm{H}_{6}$ is a rare example of a hexatopic ligand exhibiting an octahedral arrangement of carboxylic acid groups, ${ }^{8,29}$ we sought to explore the solid-state structure of this compound. Crystallization of 
L1- $\mathrm{H}_{6}$ from a mixture of acetic acid and methanol afforded crystals suitable for X-Ray analysis (see ESI $\dagger$ ). $\mathbf{L 1}-\mathrm{H}_{6}$ crystallizes in the triclinic space group $P \overline{1}$ (No. 2) and the unit cell contains three crystallographically distinct molecules of $\mathbf{L 1}-\mathbf{H}_{6}$. Two of these are linear (with the central oxygen atoms sitting on centres of symmetry) while the third molecule is slightly bent with a $\mathrm{Si}-\mathrm{O}-\mathrm{Si}$ bond angle of $170.76(18)^{\circ}$. In all three cases, the tris(4-carboxyphenyl)silyl groups are staggered with respect to one another (looking down the respective $\mathrm{Si}-\mathrm{O}-\mathrm{Si}$ axes) disposing the carboxylic acid groups in a pseudo-octahedral geometry. The acid groups in $\mathbf{L 1}-\mathrm{H}_{6}$ aggregate through dimeric hydrogenbonding interactions into a cubic crystalline network with H-bonding $\mathrm{O} \cdots \mathrm{O}$ distances in the range 2.57-2.69 $\AA$, typical of strong hydrogen bonds. ${ }^{30-32}$

The molecules of $\mathbf{L 1}-\mathrm{H}_{6}$ assemble via dimeric hydrogen bonding interactions to give a unique structure comprising of triply interpenetrating 3D nets with $1 \mathrm{D}$ polymeric chains sited within the remaining pores (Fig. 1). The 3D assemblies can be considered as 6-c pcu nets with the 6-c vertices centred on the siloxane oxygen of the $\mathbf{L} \mathbf{1}-\mathrm{H}_{6}$ molecules (Fig. 1a). All six octahedrally disposed carboxylic acids on the $\mathbf{L 1}-\mathrm{H}_{6}$ molecules are involved in hydrogen bonding to neighbouring molecules within these nets. An alternative topological interpretation in which each 6-c vertex is replaced by two 4-c vertices, each centred on a tetrahedral silicon atom, gives the derived 4-c dia net. The calculated accessible void space ${ }^{33}$ for one of these 3D-structures is approximately $85 \%$ of its overall volume, and satisfactory

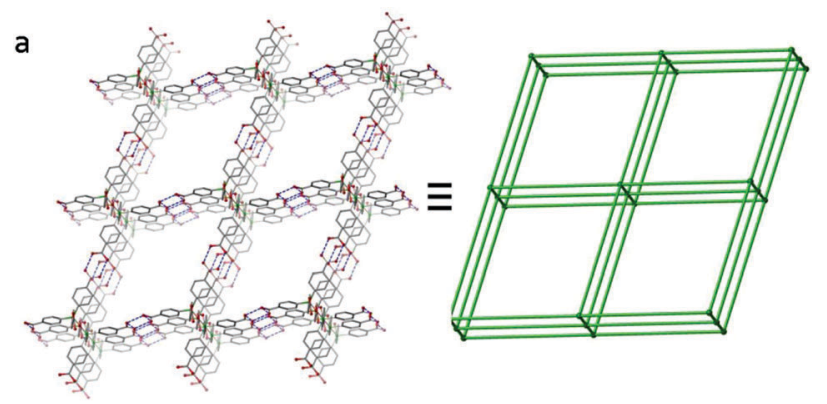

b

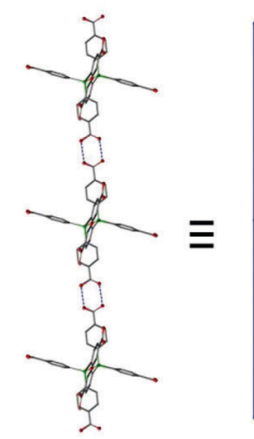

c

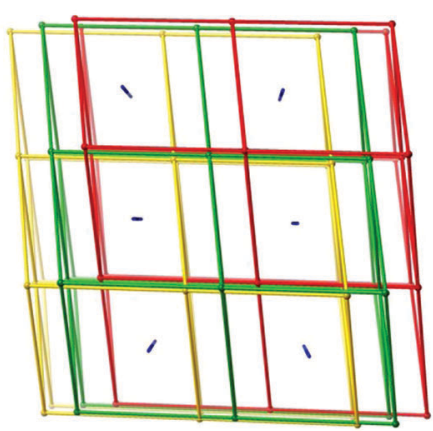

Fig. 1 (a) $\mathrm{H}$-Bonding of $\mathbf{L} \mathbf{1}-\mathrm{H}_{6}$ molecules to afford a pcu net and the equivalent topology diagram (b) arrangement of linear $\mathbf{L} 1-\mathrm{H}_{6}$ molecules to form one-dimensional supramolecular polymeric chains (c) a topological view of the triply interpenetrated network with $1 \mathrm{D}$ chains residing in the pores along [ [ $\left.\begin{array}{lll}0 & 1\end{array}\right]$. Colour scheme for chemical structures: $O$, red; C, grey; $\mathrm{Si}$, green; $\mathrm{H}$-bonds represented by dashed lines. packing is achieved by mutual interpenetration of two additional nets to afford a triply interlocked system (Fig. 1c). In addition, one dimensional channels still remain along the $\left[\begin{array}{lll}1 & 0 & 1\end{array}\right]$ crystal direction and these are filled by infinite 1D-chains of $\mathbf{L} \mathbf{1}-\mathbf{H}_{6}$ molecules that hydrogen bond through only two carboxyl groups as shown in Fig. 1b. The remaining four carboxylic acid groups on these molecules do not engage in any inter-molecular interactions. The overall porosity for this structure is consequently low, with a calculated solvent-accessible void volume of $4709 \AA^{3}$ per unit cell or just $22 \%$ of the unit cell volume. ${ }^{33}$ Efforts to exploit $\mathbf{L 1}-\mathrm{H}_{6}$ in the preparation of a non-interpenetrated hydrogenbonded array are ongoing.

We then turned our attention to the complexation of $\mathbf{L 1}-\mathrm{H}_{6}$ with transition metals for the generation of MOF materials. Reaction of L1- $\mathrm{H}_{6}$ with $\mathrm{Zn}\left(\mathrm{NO}_{3}\right)_{2} \cdot 6 \mathrm{H}_{2} \mathrm{O}$ in DMF at $85{ }^{\circ} \mathrm{C}$ in a sealed vial for 2 days afforded colourless needle-like crystals of IMP-18, where IMP is short for Imperial College London. These crystals were characterised by single crystal X-ray analysis to be $\left[\mathrm{Zn}_{3}(\mathbf{L 1})\left(\mathrm{H}_{2} \mathrm{O}\right)_{3}\right] \cdot 7 \mathrm{DMF}$ and the bulk purity of the sample was confirmed by powder X-ray diffraction (Fig. S3, ESI $\dagger$ ). ${ }^{34}$ The crystals were found to comprise of a porous 3D-connected MOF built from discrete bimetallic zinc paddle-wheel nodes linked together by the fully deprotonated ligand L1 (Fig. 2). The siloxane linkages in the $\mathbf{L 1}$ ligands are close to linear [ $\angle \mathrm{Si}-\mathrm{O}-\mathrm{Si} 176.0(12)$ and $167.9(17)^{\circ}$ ] with staggered aryl groups, resulting in the six carboxylate branches being arranged in a pseudo-octahedral disposition. In order to better understand the framework topology the $\mathrm{Zn}_{2}$-dimer can be reduced to a 4-c node and the $\mathbf{L 1}$ ligand reduced to a 6-c node to give a $(4,6)$-c fsy basic net, rarely encountered in MOFs. ${ }^{35,36}$ After theoretical removal of both the coordinated and non-coordinated solvent, PLATON ${ }^{33}$ estimates the solvent-accessible void volume for IMP-18 to be $9006 \AA^{3}$ or $59 \%$ of the unit cell volume. MOFs with hexatopic linkers remain relatively few in number and the majority of those reported feature ligands of hexagonal shape. ${ }^{29,37}$ An alternative topological description in which the 6-c ligand based vertex is replaced by two 4-c silicon centred vertices gives a new $(4,4,4)$-connected topology whose point symbol is $\left\{4 \cdot 6^{3} \cdot 8^{2}\right\}_{4}\left\{4^{2} \cdot 6^{2} \cdot 8^{2}\right\}_{2}\left\{6^{2} \cdot 8^{4}\right\}$ (see also Fig. S2, ESI $\dagger$ ). PXRD measurements on a desolvated IMP-18 sample showed retention of the structure, albeit with slight broadening of the diffraction peaks. Initial sorption analysis studies on IMP-18 show a reversible type-I $\mathrm{N}_{2}$ adsorption isotherm at $77 \mathrm{~K}$ (Fig. S5, ESI $\dagger$ ) with a calculated BET surface area of $358 \mathrm{~m}^{2} \mathrm{~g}^{-1}$.

The siloxane linkage in $\mathbf{L 1}-\mathrm{H}_{6}$ is susceptible to base cleavage. Indeed treatment of $\mathbf{L 1}-\mathrm{H}_{6}$ with an excess of $1 \mathrm{M} \mathrm{NaOH}$ affords, after protonation, tris(4-carboxyphenyl)silanol $\left(\mathbf{L} 2-\mathbf{H}_{3}\right) \cdot \mathbf{L} \mathbf{2}-\mathbf{H}_{3}$ is a novel and interesting linker since, in addition to the coordinating abilities of the carboxylate groups, the $\mathrm{Si}-\mathrm{OH}$ group is a good hydrogen bond donor ${ }^{38}$ and a potential site for further functionalization of the ligand (or post-synthetic modification of derived MOFs). Silanol-based linkers are not common in the MOF literature but Sun and co-workers have reported two 3D frameworks based on biphenyl-substituted silanols. ${ }^{39,40}$

The reaction of tricarboxylic acid $\mathbf{L 2}-\mathrm{H}_{3}$ with $\mathrm{Zn}\left(\mathrm{NO}_{3}\right)_{2} \cdot 6 \mathrm{H}_{2} \mathrm{O}$ in a $2: 1$ mixture of DMF and $\mathrm{H}_{2} \mathrm{O}$ at $80{ }^{\circ} \mathrm{C}$ for 2 days afforded 


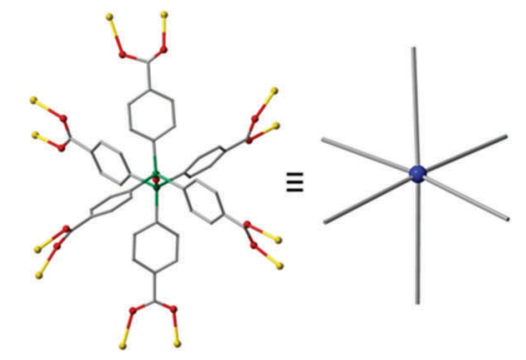

b

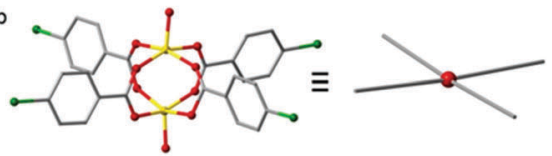

$c$

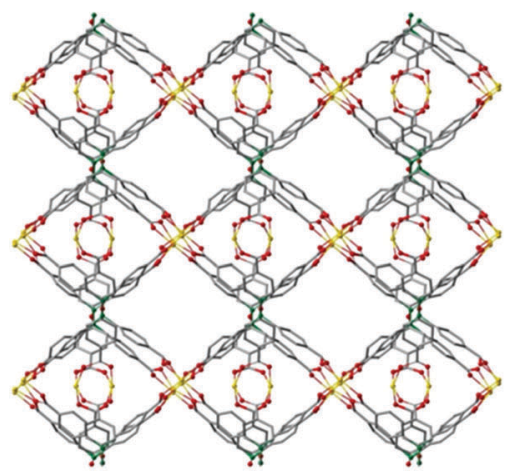

d

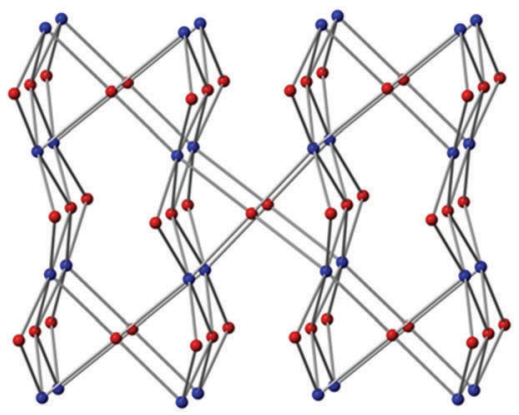

Fig. 2 (a) Coordination environment of L1 in IMP-18 and corresponding representation in topology diagram (b) arrangement of binuclear zinc paddlewheel SBUs in IMP-18 (c) section of IMP-18 viewed from the 010 crystallographic direction - disorder, solvent molecules and hydrogen atoms omitted for clarity. Colour scheme: Zn, gold; O, red; C, grey; Si, green (d) schematic representation of the fsy network showing the 4-connected Zn SBU nodes (red) and the 6-connected silicon-based nodes (blue).

colourless blade-like crystals. These crystals were characterised by single crystal X-ray analysis to be $\left[\mathrm{Zn}_{2}(\mathbf{L} 2)(\mathrm{OH})\left(\mathrm{H}_{2} \mathrm{O}\right)(\mathrm{DMF})\right]$. $2 \mathrm{H}_{2} \mathrm{O} \cdot 3 \mathrm{DMF}$ (IMP-19) and the bulk purity of the sample was confirmed by powder X-ray diffraction (Fig. S7, ESI $\dagger$ ). The crystals were found to comprise 2D polymeric sheets built from tetrametallic nodes (comprising four $\mathrm{Zn}$ atoms held together by two $\mu_{3}$-bridging hydroxides) linked together by the triply deprotonated L2 (Fig. 3) to give a (3,6)-connected net of kgd topology.

These $2 \mathrm{D}$ sheets can be considered to further assemble into a 3D networked structure through hydrogen bonding between the peripheral silanol group of an adjacent layer (H-bond donor) a

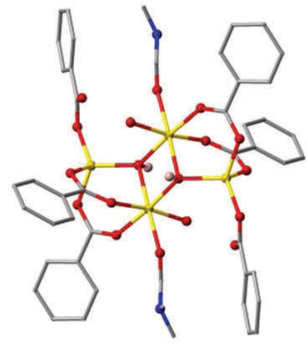

b

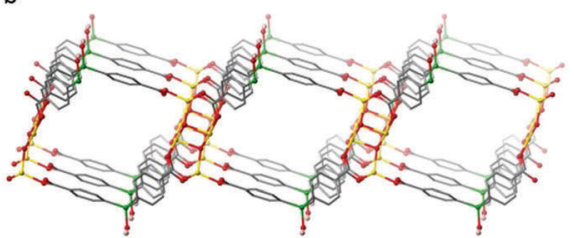

C

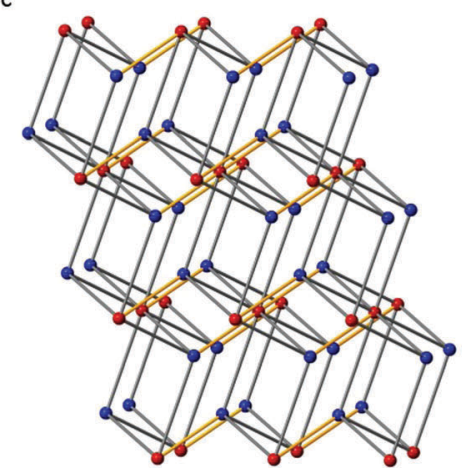

Fig. 3 (a) Structure of tetranuclear zinc SBUs in IMP-19 - disorder, solvent molecules and non-silanol hydrogen atoms omitted for clarity. Colour scheme: Zn, gold; O, red; C, grey; Si, green; $\mathrm{H}$, pink. (b) Portion of a single layer of IMP-19 showing pores along the crystallographic $b$ axis. (c) Schematic representation of the flu network showing the 6-connected Zn SBU nodes (red) and the 4-connected silicon-based nodes (blue) with hydrogen bonding interactions in yellow.

and the non-coordinated oxygen atom of the $\mathbf{L} 2$ monodentate carboxylate group with a typical D-H $\cdots$ A distance of $1.88 \AA{ }^{41}$ Considering these hydrogens bonds as topological connections, the overall supramolecular structure of IMP-19 is determined by TOPOS $^{42}$ to be a 4,8 -connected net of flu topology. The IMP-19 framework has solvent-filled channels with the largest window size being $c a .12 \times 12 \AA^{2}$. After theoretical removal of both the coordinated and non-coordinated solvent, the PLATON ${ }^{33}$ estimated solvent-accessible void volume for IMP-19 is $2070 \AA^{3}$ or $58 \%$ of the unit cell volume. However, in practice evacuation of the material led to its decomposition and a complete loss of porosity.

In summary, the novel siloxane-based hexacarboxylic acid L1- $\mathrm{H}_{6}$ has been prepared and shown to self-assemble into a 3D triply interpenetrated hydrogen-bonded organic framework with guest 1D H-bonded chain polymers in its pores. Treatment of L1- $\mathrm{H}_{6}$ with $\mathrm{Zn}$ (II) gives IMP-18, which in our knowledge is the first 3D-connected MOF structure which incorporates a disiloxanebased linker. We believe these initial results will lead to the use of other siloxane scaffolds in the assembly of porous MOFs, including the use of cyclic and cage-like polysiloxane linkers. 
We are also interested in further investigating the use of silanol-based linkers in the preparation of porous MOFs.

The Imperial College President's PhD Scholarship Scheme (LD) and the EPSRC (EP/M507878/1) are acknowledged for funding this work. We are grateful to A. R. Kucernak for assistance with BET measurements. Special thanks to Amanda Zammit and Yu Hin Lai for assistance with some of the experimental work.

\section{Conflicts of interest}

There are no conflicts to declare.

\section{Notes and references}

1 H. Furukawa, K. E. Cordova, M. O'Keeffe and O. M. Yaghi, Science, 2013, 341, 1230444.

2 S. Kitagawa, Chem. Soc. Rev., 2014, 43, 5415-5418.

3 W. Lu, Z. Wei, Z.-Y. Gu, T.-F. Liu, J. Park, J. Park, J. Tian, M. Zhang, Q. Zhang, T. Gentle III, M. Bosch and H.-C. Zhou, Chem. Soc. Rev., 2014, 43, 5561-5593.

4 F. A. Almeida Paz, J. Klinowski, S. M. F. Vilela, J. P. C. Tome, J. A. S. Cavaleiro and J. Rocha, Chem. Soc. Rev., 2012, 41, 1088-1110.

5 R. P. Davies, R. J. Less, P. D. Lickiss, K. Robertson and A. J. P. White, Inorg. Chem., 2008, 47, 9958-9964.

6 R. P. Davies, R. Less, P. D. Lickiss, K. Robertson and A. J. P. White, Cryst. Growth Des., 2010, 10, 4571-4581.

7 R. P. Davies, P. D. Lickiss, K. Robertson and A. J. P. White, Aust. J. Chem., 2011, 64, 1239-1246.

8 R. P. Davies, P. D. Lickiss, K. Robertson and A. J. P. White, CrystEngComm, 2012, 14, 758-760.

9 I. Timokhin, J. Baguna Torres, A. J. P. White, P. D. Lickiss, C. Pettinari and R. P. Davies, Dalton Trans., 2013, 42, 13806-13808.

10 I. Timokhin, A. J. P. White, P. D. Lickiss, C. Pettinari and R. P. Davies, CrystEngComm, 2014, 16, 8094-8097.

11 B. Sels and L. Kustov, Zeolites and Zeolite-like Materials, Elsevier, 2016.

12 P. Eliasova, M. Opanasenko, P. S. Wheatley, M. Shamzhy, M. Mazur, P. Nachtigall, W. J. Roth, R. E. Morris and J. Cejka, Chem. Soc. Rev., 2015, 44, 7177-7206.

13 P. Van Der Voort, D. Esquivel, E. De Canck, F. Goethals, I. Van Driessche and F. J. Romero-Salguero, Chem. Soc. Rev., 2013, 42, 3913-3955.

14 J. G. Croissant, X. Cattoen, M. Wong Chi Man, J.-O. Durand and N. M. Khashab, Nanoscale, 2015, 7, 20318-20334.

15 D. B. Cordes, P. D. Lickiss and F. Rataboul, Chem. Rev., 2010, 110, 2081-2173.
16 Q. Ye, H. Zhou and J. Xu, Chem. - Asian J., 2016, 11, 1322-1337.

17 M. S. Deshmukh, T. Vijayakanth and R. Boomishankar, Inorg. Chem., 2016, 55, 3098-3104.

18 A. Vlad, M. Cazacu, M.-F. Zaltariov, A. Bargan, S. Shova and C. Turta, J. Mol. Struct., 2014, 1060, 94-101.

19 A. Vlad, M.-F. Zaltariov, S. Shova, G. Novitchi, C.-D. Varganici, C. Train and M. Cazacu, CrystEngComm, 2013, 15, 5368-5375.

20 C. Racles, S. Shova, M. Cazacu and D. Timpu, Polymer, 2013, 54, 6096-6104.

21 D. M. L. Goodgame, P. D. Lickiss, S. J. Rooke, A. J. P. White and D. J. Williams, Inorg. Chim. Acta, 2003, 343, 61-73.

22 M. Wander, P. J. C. Hausoul, L. A. J. M. Sliedregt, B. J. van Steen, G. van Koten and R. J. M. Klein Gebbink, Organometallics, 2009, 28, 4406-4415.

23 M. Sridhar, B. C. Ramanaiah, C. Narsaiah, M. Kumara Swamy, B. Mahesh and M. K. Kumar Reddy, Tetrahedron Lett., 2009, 50, 7166-7168.

24 S. Wang, L. Tan, C. Zhang, I. Hussain and B. Tan, J. Mater. Chem. A, $2015,3,6542-6548$.

25 R. Dawson, D. J. Adams and A. I. Cooper, Chem. Sci., 2011, 2, 1173-1177.

26 Y.-F. Han, Y.-X. Yuan and H.-B. Wang, Molecules, 2017, 22, 266-300.

27 J. Lü and R. Cao, Angew. Chem., Int. Ed., 2016, 55, 9474-9480.

28 F. Hu, C. Liu, M. Wu, J. Pang, F. Jiang, D. Yuan and M. Hong, Angew. Chem., Int. Ed., 2017, 56, 2101-2104.

29 M. Li, D. Li, M. O'Keeffe and O. M. Yaghi, Chem. Rev., 2014, 114, 1343-1370.

30 D. J. Duchamp and R. E. Marsh, Acta Crystallogr., Sect. B: Struct. Sci., 1969, 25, 5-19.

31 M. Bailey and C. J. Brown, Acta Crystallogr., 1967, 22, 387-391.

32 R. Alcala and S. Martinez-Carrera, Acta Crystallogr., Sect. B: Struct. Sci., 1972, 28, 1671-1677.

33 A. Spek, J. Appl. Crystallogr., 2003, 36, 7-13.

34 S. J. Coles and P. A. Gale, Chem. Sci., 2012, 3, 683-689.

35 S. Zhang, W. Shi, L. Li, E. Duan and P. Cheng, Inorg. Chem., 2014, 53, 10340-10346.

36 Y. He, Z. Zhang, S. Xiang, H. Wu, F. R. Fronczek, W. Zhou, R. Krishna, M. O'Keeffe and B. Chen, Chem. - Eur. J., 2012, 18, 1901-1904.

37 S. Kaskel, The chemistry of metal-organic frameworks: synthesis, characterization, and applications, John Wiley \& Sons, 2016.

38 P. D. Lickiss, Adv. Inorg. Chem., 1995, 42, 147-262.

39 X. Zhao, D. Sun, S. Yuan, S. Feng, R. Cao, D. Yuan, S. Wang, J. Dou and D. Sun, Inorg. Chem., 2012, 51, 10350-10355.

40 H. Ma, D. Sun, L. Zhang, R. Wang, V. A. Blatov, J. Guo and D. Sun, Inorg. Chem., 2013, 52, 10732-10734.

41 J. O. Bauer and C. Strohmann, J. Organomet. Chem., 2015, 797, $52-56$.

42 V. A. Blatov, A. P. Shevchenko and D. M. Proserpio, Cryst. Growth Des., 2014, 14, 3576-3586. 